the smallest survivor in the St James's group was $1320 \mathrm{~g}$, and, obviously, smaller babies have more problems over the first few weeks of life. My impression was, however, that the difference in weight gain between the two units was due to the type of milk used in the two centres.

During this period, the great majority of preterm babies in Leicester were given donor breast milk, the calorie content of which is variable. ${ }^{1}$ In St James's Hospital, Nenatal, one of the new formula milks for preterm babies, was given to all babies weighing under $1700 \mathrm{~g}$ whose mothers were intending to bottle feed, and breast-fed babies were given their own mother's breast milk. The authors state in their article that "delaying discharge of small preterm babies from neonatal units is difficult to justify." Unless we are convinced that donor breast milk from a human milk bank confers some immunological benefits on the baby, ${ }^{2}$ it would be fairly easy to justify giving one of the new preterm formula milks to these babies to enable more rapid weight gain which would in turn mean preterm babies going home even sooner from a unit which operates an early discharge policy.

Department of Paediatrics,

Ninewells Hospital,

Ninewells

Dundee DD1 9SY

Spencer SA, Hull D. Br Med f 1981 ;282:99-100.

2 Baum JD. The effects of pasteurization on immune factors in human milk. In: Visser $\mathrm{HK}$, ed. Nutrition and metabolism of the fetus and infant. Boston
Nijhoff, 1979:173-83.

\section{Last scene of all}

SIR,-Professor J Williamson (30 January, p 346) attacks the statement by Professor P H Millard (12 December, p 1559) that patients with dementia require computed tomography. Professor Williamson refers to the paper by Smith and Kiloh ${ }^{1}$ from Sydney as if it lends support to his view, though Professor Millard cited the same paper but drew different conclusions.

Professor Williamson states, "The Sydney workers do not specify the ages of their patients": under a distinct subheading, "Age distribution," Smith and Kiloh give mean ages $(55.8$ years in men, 59.7 years in women) and the range (men 23-79 years, women 33-83 years) in their series: Professor Williamson "would be most surprised if any were more than 85 ," and so would we since this is above the upper limit of the range explicitly stated in the paper. He goes on to say that Professor Millard omits to point out that the yield of "potentially reversible causes" of dementia in those aged over 65 was lower than in patients aged 45-64 years: true. Professor Williamson himself omits that not a single one of the patients under 45 years old was found to have a "potentially reversible cause." Is he going to take his argument to its logical conclusion, that patients with dementia below the age of 45 should not have routine computed tomography either? The Sydney series was collected over four and a half years, up to the end of 1977; and only "in the last few months of the study" was computed tomography available. This fact and the selection processes referred to by Professor Williamson make it difficult to derive any generally applicable guidelines on the value of computed tomography in unselected patients with dementia at any age.

If Professor Williamson is arguing that for economic and logistic reasons we cannot afford routine computed tomography scans for all demented patients, then that is a legitimate debating point. Professor Millard did indeed address this problem in the sixth paragraph of his leading article. However, Professor Williamson is urging us to be selective in our use of computed tomography before any solid body of knowledge is available on which to base such selection. For example, in Sydney as in other centres, ${ }^{2}$ the commonest "potentially treatable cause" of dementia was normal-pressure hydrocephalus. Neither the prevalence nor the natural history of normal-pressure hydrocephalus in the elderly is known and the best means of diagnosis and treatment are uncertain..$^{3}$ What is certain is that our ignorance will continue until properly mounted studies of dementia in the elderly have been carried out, including evaluation of the role of computed tomography in investigation.

By documenting the results of their experience, the neuropsychiatric unit in Sydney and Professor Millard's own group 4 are at least trying to help answer the difficult question of how to deal with the swelling numbers of the aged and demented. Professor Williamson does such workers less than justice by misreporting what they have written and weakens his own standpoint, for which he supplies no factual basis. He may be right that computed tomography will not become routine for all demented patients for reasons of supply and demand, but Professor Millard feels that the need should be met. Smith and Kiloh presumably fall into the latter camp, since they write, "It is recommended that all patients with a provisional diagnosis of dementia be investigated early in the course of their illnesses," and also "Any investigation of demented patients should include an estimation of serum-vitamin- $B_{12}$, thyroid function tests, and a computed tomography scan."

R S BRIGGS

University Department of Geriatric Medicine,

Southampton General Hospital,

'Smith JS, Kiloh LG. Lancet 1981 ; i:824-7. Harrison MJG, Marsden CD. Arch Neurol 1977;34: 199.

1981 RS, Castleden CM, Alvarez AS. Age Ageing Oram JJ, Edwa

$1981 ; 27: 216-23$.

\section{Augmented home nursing as an}

alternative to hospital care for chronic elderly invalids

SIR, - I was very interested to read the article by $\operatorname{Dr} F \mathrm{~J}$ Gibbins and others (30 January, p 330) suggesting that augmented home care for patients might save money by reducing the need for hospital beds. The central question that this study needs to answer is whether the establishment of an augmented home care service reduces the need (or demand) for hospital beds sufficiently to recoup the cost of the new service by freeing resources. But unfortunately this study fails to answer the question on several counts.

(1) The hospital (control) and augmented home care (trial) groups are not comparable, the control group being physically, mentally, and medically worse. Indeed, consideration of table II suggests that the type of care received (normal home care, augmented home care, or hospital care) is related in a proportional way to the initial level of disability, and that the degree of disability may well dictate the type of care given. This in turn suggests that many of those receiving extra home care might never have been admitted to hospital. If this is so, then this new service is in fact an increased cost to the community as many of its recipients would otherwise have received normal home care.

(2) Nine $(37 \%)$ of the 24 patients kept at home died, as against two $(18 \%)$ of the 11 in hospital, despite the fact that the former were initially less severely affected. While this difference may well be due to chance (given the very small numbers in this study), future studies will need to show that the lower cost of home care is not simply due to a higher death rate in this group.

(3) Five of the 24 patients in the trial group were anyway eventually admitted to hospital, yet the cost of their hospital care does not seem to appear in the comparative analysis of costs.

This study does demonstrate that the cost of this service is less than the cost of hospital care but it fails to demonstrate that providing this service in any way lessens the need or demand for hospital care. In order to demonstrate that any new service is cost effective one needs to perform a controlled trial just as the controlled trial is used to demonstrate the effectiveness of any new drug. Inevitably large numbers of patients are needed, but it is essential to demonstrate the cost effectiveness of any new service before advocating that it is taken up nationally.

DERICK T WADE

\section{Avon Neurological/Strok}

Rehabilitation Unit,

Frenchay Hospital,

SIR,-In their article on augmented home nursing as an alternative to hospital care for chronic elderly invalids (30 January, p 330), Dr F J Gibbins and others have shown, largely on the grounds of cost, the feasibility of having carefully selected elderly invalids looked after at home. While such a scheme could never sustain the vast majority of those long-stay patients who are totally dependent and require constant supervision and help for most of their activities of daily living, even for the carefully selected group of patients mentioned in the study the quality of care would almost certainly be inadequate if these patients were to be left unattended for many hours during the day and up to 11 hours (9 pm-8 am) in the night. To base any study of the care of the chronic elderly invalids on cost only is probably not justified since the quality of care provided certainly matters most. Nevertheless, other studies failed to find whether the domiciliary care of such elderly patients was any cheaper, 1 and the marginal cost difference between residential care and intensive domiciliary care was small or even favoured the former for some groups of people. ${ }^{2}$

In any case it sounds strange and inconceivable that elderly infirm people incapable of self-care should be recommended for part III accommodation (welfare homes) whereas much more severely incapacitated people (mostly over 75 years, living alone, immobile, incontinent, and in danger of developing pressure sores) should be maintained in their own homes by some kind of augmented domiciliary care. If such augmented care can keep these severely disabled elderly patients at home, surely the lesser disabled elderly people residing in the welfare homes can be looked after far more easily with much less extra help in their own homes.

To provide better care at low cost for this selected group of chronic elderly invalids, 